\title{
Bone Marrow Stem Cell Paracrine Factors and Their Role the Restoration of Damaged Tissues and Organs
}

\author{
Zurab Kakabadze ${ }^{1}$, Nodar Kipshidze ${ }^{2}$ and Nicholas Kipshidze*3 \\ ${ }^{1}$ Department of Clinical Anatomy, Tbilisi State Medical University Tbilisi, Georgia \\ ${ }^{2}$ New York University Langone Health, USA \\ ${ }^{3}$ New York Cardiovascular Research, USA

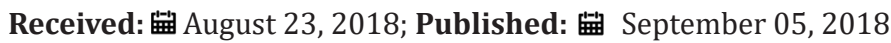 \\ *Corresponding author: Nicholas Kipshidze, New York Cardiovascular Research, 10128, USA
}

\begin{abstract}
This mini review focuses on the freeze-dried bone marrow stem cell paracrine factors and their role in the restoration of damaged tissues and organs. Recently, many authors report that freeze-dried bone marrow stem cells paracrine factors stimulate tissue regeneration via effects on cell homing/targeting, neovascularization, anti-inflammatory effects, and endogenous cell stimulation. A review of the literature demonstrated that bone marrow stem cells, following freeze-drying, preserved the function of paracrine factors and provided stronger and more durable effects on cellular proliferation, survival, and wound regeneration compared to a fresh medium or other types of synthetic growth factors. Conducting preliminary clinical investigations indicated that biologically active bone grafts containing freeze-dried bone marrow stem cell paracrine factors may be used for the reconstruction of large mandible bone defects following tumor resection. Despite the encouraging results obtained, it is too early to talk about the possibility of using freeze-dried bone marrow stem cell paracrine factors in clinical practice. Further experimental and clinical studies with greater rigor are needed to determine the effectiveness of using freeze-dried bone marrow stem cell paracrine factors.
\end{abstract}

\section{Introduction}

In recent years, there has been a growing interest in freezedried plasma and red blood cells, freeze-dried platelet-rich plasma (PRP), and freeze-dried bone marrow stem cell. Specifically, there is an interest in freeze-dried bone marrow stem cell paracrine factors and their role in the restoration of damaged tissues and organs. Pietramaggiori G [1] report that freeze-dried PRP alone or in combination with micronized dermis increased wound tissue revascularization and proliferation compared to spontaneous healing. Peng Y [2] report that bone marrow mesenchymal stem cells, following freeze-drying, preserved the function of paracrine factors and provided stronger and durable effects on cellular proliferation, survival, and wound regeneration when compared to fresh medium or other types of synthetic growth factors. Many authors report that bone marrow stem cells paracrine factors stimulate tissue regeneration via effects on cell homing/targeting [3], neovascularization [4], anti-inflammatory effects [5] and endogenous cell stimulation [6]. It was hypothesized that freezedried bone marrow stem cell paracrine factors may be used for the reconstruction of large mandible bone defects following tumor resection. Preliminary clinical investigations [7] indicated that biologically active bone grafts containing freeze-dried bone marrow stem cell paracrine factors may be used for the reconstruction of large mandible bone defects following tumor resection. Studies have shown that bone marrow stem cells paracrine factors demonstrated the same regenerative capacities as stem cell injection.

\section{Conclusion}

Preliminary clinical investigations have demonstrated that freeze-dried bone marrow stem cell paracrine factors increased osteoconduction, osteoinduction, and osseointegration of decellularized bovine bone graft. Further studies are needed to better understand the biology and pathophysiology of freezedrying bone marrow stem cells and to estimate the effectiveness of free-drying bone marrow in the clinical setting.

\section{References}

1. Pietramaggiori G, Scherer SS, Mathews JC, Alperovich M, Yang HJ, et al. (2008) Healing modulation induced by freeze-dried platelet-rich plasma and micronized allogenic dermis in a diabetic wound model. Wound Repair Regen 16(2): 218-225

2. Peng Y, Xuan M, Zou J, Liu H, Zhuo, et al. (2015) Freeze-Dried Rat Bone Marrow Mesenchymal Stem Cell Paracrine Factors: A Simplified Novel Material for Skin Wound Therapy. Tissue Eng Part A 21(5-6): 1036-1046.

3. Shi M, Li J, Liao L, Chen B, Li B, et al. (2007) Regulation of CXCR4 expression in human mesenchymal stem cells by cytokine treatment: Role in homing efficiency in NOD/SCID mice. Haematologica 92(7): 897904.

4. Hamano K, Nishida M, Hirata K, Mikamo A, Li TS, et al. (2001) Local implantation of autologous bone marrow cells for therapeutic 
angiogenesis in patients with ischemic heart disease-clinical trial and preliminary results. Japanese Circulation Journal 65(9): 845-847.

5. Chen G, Nayan M, Duong M, Asenjo JF, Ge Y, et al. (2010) Marrow stromal cells for cell-based therapy: The role of antiinflammatory cytokines in cellular cardiomyoplasty. Ann Thorac Surg 90(1): 190-197.

6. Bi B, Schmitt R, Israilova M, Nishio H, Cantley LG (2007) Stromal cells protect against acute tubular injury via an endocrine effect. J Am Soc Nephrol 18(9): 2486-2496.

ISSN: 2574-1241

DOI: 10.26717/BJSTR.2018.08.001699

Nicholas Kipshidze. Biomed J Sci \& Tech Res

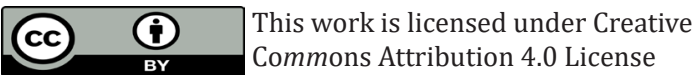

Submission Link: https://biomedres.us/submit-manuscript.php
7. Kakabadze A, Mardaleishvili K, Loladze G, Karalashvili L, Chutkerashvili G, et al. (2017) Reconstruction of mandibular defects with autogenous bone and decellularized bovine bone grafts with freeze-dried bone marrow stem cell paracrine factors. Oncol Lett 13(3): 1811-1818.

$\begin{array}{ll}\text { BIOMEDICAL } & \text { Assets of Publishing with us } \\ \text { RESEARCHES } & \text { - Global archiving of articles } \\ \text { - Immediate, unrestricted online access } \\ \text { https://biomedres.us/ }\end{array}$

